\title{
Aplikasi Reservasi Parkir Inap Menggunakan Metode Fishbone Diagram dan QR-Code
}

\author{
Yostian Ari Sujarwo ${ }^{[1]^{*}}$, Anita Ratnasari ${ }^{[2]}$ \\ Fakultas Ilmu Komputer Universitas Mercubuana ${ }^{[1], \text { [2] }}$ \\ J1.Raya Meruya Selatan, Kembangan, Jakarta, 11650, Indonesia \\ 41813110100@student.mercubuana.ac.id ${ }^{[1]}$, anita.ratnasari@mercubuana.ac.id ${ }^{[2]}$
}

\begin{abstract}
Currently parking system that is running in $\mathbf{P t}$. Sanggraha Daksamitra still uses a conventional parking system. When the driver wants to do parking, driver first presses the analog button on the parking gate to get a parking ticket. Lack of maintenance on the parking gate causes vehicle jams in the parking entrance area. To minimize errors that occur, the fishbone diagram analysis method is used to analyze the problem. After the problem was found, a parking reservation was developed that used qr-code as a scanner identification in the parking system. The system produced in this study is expected to facilitate parking drivers who want to park their vehicles in the parking area of Pt. Sanggraha Daksamitra. The results of this system will be tested using blackbox testing.
\end{abstract} code

Keywords - parking reservation system, fishbone diagram, qr-

\begin{abstract}
Abstrak-Saat ini sistem parkir yang sedang berjalan di Pt. Sanggraha Daksamitra masih menggunakan sistem parkir yang konvensional. Saat pengendara ingin melakukan parkir inap, pengendara terlebih dahulu menekan tombol analog pada palang pintu parkir untuk mendapatkan tiket parkir. Kurangnya perawatan pada mesin palang pintu parkir menyebabkan sering terjadi penumpukan kendaraan di area pintu masuk parkir. Untuk meminimalisir setiap kesalahan yang terjadi maka digunakan digunakan metode analisa fishbone diagram untuk menganalisa masalah. Setelah masalah ditemukan maka dikembangkan sistem reservasi parkir yang menggunakan qrcode sebagai alat identifikasi scanner pada sistem parkir. Sistem yang dihasilkan dalam penelitian ini diharapkan dapat mempermudah pengendara parkir yang ingin memarkirkan kendaraannya di area parkir Pt. Sanggraha Daksamitra. Hasil penelitian ini nantinya diuji menggunakan blackbox testing.
\end{abstract}

Kata Kunci-sistem reservasi parkir, fishbone diagram, qr-code

\section{PENDAHULUAN}

Di era komputerisasi yang sudah mengalami perkembangan jaman teknologi yang cukup pesat didunia digital, seiring dengan penggunaan digital pada sistem parkir untuk kendaraan. Dari sistem parkir manual sudah tergeser oleh sistem parkir otomatis atau auto sebagai sistem parkir tersebut.
Pada sistem parkir lama memiliki kesulitan ketika masuk tempat parkir menggunakan sistem tombol analog untuk membukakan palang pintu dan mengeluarkan struk parkir, belum lagi bila terjadi masalah kerusakan pada mesin palang pintu yang di sebabkan kurangnya perawatan oleh pihak teknisi, yang menimbulkan penumpukan kendaraan akibat antrian panjang saat masuk parkiran. Serta struk yang hilang, rusak, atau basah ketika ingin keluar dari tempat parkir.

Untuk meminimalisir setiap kesalahan. Maka dilakukan analisa masalah menggunakan fishbone diagram yang kemudian dilanjutkan dengan mengembangkan sistem parkir menggunakan kode QR (Quick Response code or QR Code).

Qr-Code mampu menyimpan semua jenis data, seperti data numerik/angka, alphanumeric, biner. Selain itu Qr-Code memiliki tampilan yang lebih kecil daripada barcode. Hal ini dikarenakan Qr-Code mampu menampung data secara horizontal dan vertical, jadi secara otomatis ukuran dari tampilan gambar Qr-Code mampu memperbaiki kesalahan sampai dengan $30 \%$, tergantung dengan ukuran atau versinya. Oleh karena itu, walaupun sebagian simbol Qr-Code kotor ataupun rusak, data tetap dapat disimpan dan dibaca [1].

Gayatri N. Hainalkar, dan Mousami S. Vanjale [2] menciptakan sistem smart parking yang melakukan reservasi online menggunakan sensor pada tempat parkir untuk mengetahui tempat tersebut sudah diisi atau belum. Untuk melakukan reservasi pada sistem ini, mereka masih menggunakan situs website yang sudah di rancang dengan bagus. Akan tetapi pembuatan sistem tersebut harus menggunakan modal yg mahal agar sistem tersebut bisa digunakan.

Dalam penelitian lebih lanjut kode QR dapat di gunakan bagi kendaraan (user) yang awalnya menggunakan struk parkir sebagai media pemindaian data pelanggan parkir tersebut. dengan pemindaian melalui kode QR pelanggan parkir akan di sesuaikan dengan database melalui kamera atau aplikasi parkir yang dibuka dengan smarphone, pelanggan parkir mengetahui jam masuk, jam keluar, dan durasi jam parkir agar mempermudah bagi pelanggan parkir untuk mengetahui berapa biaya parkir perjamnya.

Secara teknis sistem ini dapat mengurangi jumlah biaya pengeluaran pada sistem parkir serta menjadi teknologi digital ramah lingkungan karena mengurangi penggunaan kertas 
sebagai struk parkir. Selain itu pula, sistem parkir ini dilengkapi dengan tata letak parkir, jadi pelanggan / user dapat memilih tempat parkir yang dia inginkan selama tempat parkir itu masih kosong.

\section{TINJAUAN PUSTAKA}

\section{A. Definisi Parkir}

Parkir adalah keadaan tidak bergerak dari suatu kendaraan yang bersifat sementara. Suatu kendaraan tidak mungkin bergerak terus, pada suatu saat dia harus berhenti untuk sementara waktu (menurunkan muatan) atau berhenti cukup lama yang disebut parkir [3].

Parkir adalah suatu keadaan dimana suatu kendaraan yang bersifat sementara ditinggalkan oleh pengemudinya. Dan definisi menurut undang-undang nomor 22 tahun 2009 tentang Lalu Lintas dan Angkutan Jalan, Bab I Ketentuan Umum, pada Pasal 1 angka 15 dan 16 tertulis sebagai berikut : Pasal 1 Dalam Undang- Undang ini yang dimaksud dengan: 15. Parkir adalah keadaan Kendaraan berhenti atau tidak bergerak untuk beberapa saat dan ditinggalkan pengemudinya. 16. Berhenti adalah keadaan kendaraan tidak bergerak untuk sementara dan tidak ditinggalkan pengemudinya.

Berdasarkan beberapa pendapat para ahli diatas, dapat diambil kesimpuan bahwa parker adalah tempat pemberhentian kendaraan dalam waktu lama atau pendek sesuai dengan kebutuhan pengendara. Keadaan dimana suatu kendaraan berhenti dan ditinggalkan oleh pemiliknya untuk waktu yang tidak bisa ditentukan.

\section{B. Definisi Qr-Code}

Qr-Code adalah teknik yang mengubah data tertulis menjadi kode - kode 2 dimensi yang tercetak dalam suatu media yang lebih ringkas. Qr-Code pertama kali diperkenalkan oleh perusahaan jepang yang bernama DensoWave pada tahun 1994. QR adalah singkatan dari Quick Response karena ditujukan untuk diterjemahkan isinya dengan cepat. Qr-Code merupakan pengembangan dari barcode satu dimensi, Qr-Code adalah salah satu tipe dari barcode yang dapat dibaca dengan menggunakan kamera handphone [4].

\section{Definisi Fishbone Diagram}

Ishikawa diagram atau dikenal dengan fishbone diagram adalah salah satu metode dari Seven Quality Tools yang digunakan untuk mencari penyebab dari timbulnya suatu masalah.

\section{Penelitian Terkait}

TABLE I. PENELITIAN TERDAHULU

\begin{tabular}{|c|c|c|c|c|c|}
\hline No & Sumber & $\begin{array}{c}\text { Masalah dan } \\
\text { tujuan }\end{array}$ & Metode & Hasil & Kelebihan \\
\hline \multirow{6}{*}{1} & M. T. & "Sistem parkir & Waterfal & Siste & Sistem \\
& Hidayat, & yang masih & $l$ & $\mathrm{~m}$ & yang akan \\
& "Pengem & manual dan & & memb & dibagun \\
& bangan & transaksi & & erikan & memiliki \\
& Modul & pembayaran & & kemu & kelebihan \\
& Client & yang tingkat & & dahan & dapat \\
& Pada & kesalahannya & & bagi & melihat \\
& Sistem & terhitung tinggi", & & pihak & jumlah \\
\hline
\end{tabular}

\begin{tabular}{|c|c|c|c|c|c|}
\hline No & Sumber & $\begin{array}{c}\text { Masalah dan } \\
\text { tujuan }\end{array}$ & Metode & Hasil & Kelebihan \\
\hline & $\begin{array}{c}\text { Parkir } \\
\text { Pintar } \\
\text { Berbasis } \\
\text { Quick } \\
\text { Response } \\
\text { Code } \\
\text { (QR } \\
\text { CODE), } \\
\text { e- } \\
\text { Proceedin } \\
\text { g of } \\
\text { Engineeri } \\
\text { ng, vol.6, } \\
\text { 2019[5]. }\end{array}$ & $\begin{array}{l}\text { "Menghasilkan } \\
\text { sebuah prototype } \\
\text { sistem parkir } \\
\text { berlangganan } \\
\text { dengan } \\
\text { memanfaatkan } \\
\text { teknologi } \\
\text { smartphone". }\end{array}$ & & $\begin{array}{c}\text { penge } \\
\text { lola } \\
\text { parkir } \\
\text { maup } \\
\text { un } \\
\text { pengg } \\
\text { una } \\
\text { parkir } \\
.\end{array}$ & $\begin{array}{c}\text { biaya yang } \\
\text { akan } \\
\text { dikeluarkan } \\
\text { untuk } \\
\text { setiap } \\
\text { reservasi } \\
\text { yang } \\
\text { dilakukan, } \\
\text { dan juga } \\
\text { pelanggan } \\
\text { dapat } \\
\text { memilih } \\
\text { sendiri } \\
\text { tempat } \\
\text { parkir yang } \\
\text { akan dia } \\
\text { reservasi. }\end{array}$ \\
\hline 2 & $\begin{array}{c}\text { I. G. } \\
\text { Tofik, } \\
\text { "Peranca } \\
\text { ngan } \\
\text { Sistem } \\
\text { Parkir } \\
\text { QR } \\
\text { CODE } \\
\text { Menggun } \\
\text { akan } \\
\text { Mikrokon } \\
\text { troler } \\
\text { Arduino } \\
\text { Berbasis } \\
\text { Android, } \\
\text { Seminar } \\
\text { Nasional } \\
\text { Teknolog } \\
\text { i } \\
\text { Informasi } \\
\text { dan } \\
\text { Multimed } \\
\text { ia, } \\
\text { 2017[6]. }\end{array}$ & $\begin{array}{c}\text { "Meningkatnya } \\
\text { tingkat } \\
\text { kriminalitas di } \\
\text { area parkir dan } \\
\text { juga kurang } \\
\text { nyamannya area } \\
\text { parkir, } \\
\text { "Meminimalisir } \\
\text { tingkat } \\
\text { kriminalitas dan } \\
\text { memaksimalkan } \\
\text { kenyamanan } \\
\text { dengan } \\
\text { menggunakan } \\
\text { QR Code yang } \\
\text { digunakan untuk } \\
\text { membuka palang } \\
\text { pintu parkir". }\end{array}$ & $\begin{array}{c}\text { Waterfal } \\
l\end{array}$ & $\begin{array}{c}\text { Deng } \\
\text { an } \\
\text { adany } \\
\text { a } \\
\text { sistem } \\
\text { parkir } \\
\text { yang } \\
\text { meng } \\
\text { gunak } \\
\text { an QR } \\
\text { Code, } \\
\text { penge } \\
\text { lola } \\
\text { lebih } \\
\text { muda } \\
\text { h } \\
\text { untuk } \\
\text { memb } \\
\text { erikan } \\
\text { keam } \\
\text { anan } \\
\text { dan } \\
\text { kenya } \\
\text { mana } \\
\text { n bagi } \\
\text { pengg } \\
\text { una } \\
\text { parkir }\end{array}$ & $\begin{array}{c}\text { Sistem } \\
\text { yang akan } \\
\text { dibagun } \\
\text { memiliki } \\
\text { kelebihan } \\
\text { selain } \\
\text { menggunak } \\
\text { an QR- } \\
\text { Code } \\
\text { sebagai } \\
\text { pembuka } \\
\text { palang } \\
\text { pintu } \\
\text { parkir, } \\
\text { pengguna } \\
\text { juga dapat } \\
\text { memilih } \\
\text { tempat } \\
\text { parkir yang } \\
\text { dia } \\
\text { inginkan } \\
\text { pada saat } \\
\text { reservasi. }\end{array}$ \\
\hline 3 & $\begin{array}{c}\text { A. Triagi, } \\
\text { "Sistem } \\
\text { Informasi } \\
\text { Manajem } \\
\text { en Parkir } \\
\text { Kendaraa } \\
\text { n } \\
\text { Menggun } \\
\text { akan } \\
\text { Teknolog } \\
\text { i QR } \\
\text { Code } \\
\text { Berbasis } \\
\text { Desktop", } \\
\text { Seminar } \\
\text { Teknolog } \\
\text { i } \\
\text { Majaleng } \\
\text { ka, } \\
\text { 2018[7]. }\end{array}$ & $\begin{array}{l}\text { "Belum adanya } \\
\text { manajemen } \\
\text { perparkiran di } \\
\text { Universitas } \\
\text { Majalengka dan } \\
\text { sering terjadi } \\
\text { pencurian karena } \\
\text { kurangnya } \\
\text { pengawasan } \\
\text { petugas", } \\
\text { "Membuat } \\
\text { sistem keamanan } \\
\text { parkir terjamin } \\
\text { agar identitas } \\
\text { kendaraan masuk } \\
\text { dan keluar area } \\
\text { parkir di } \\
\text { ketahui". }\end{array}$ & $\begin{array}{l}\text { Extreme } \\
\text { Program } \\
\quad \text { ming }\end{array}$ & $\begin{array}{l}\text { Deng } \\
\text { an } \\
\text { adany } \\
\text { a } \\
\text { sistem } \\
\text { ini, } \\
\text { setiap } \\
\text { kenda } \\
\text { raan } \\
\text { yang } \\
\text { masu } \\
\text { k ke } \\
\text { area } \\
\text { parkir } \\
\text { bisa } \\
\text { teride } \\
\text { ntifik } \\
\text { asi } \\
\text { dan } \\
\text { juga } \\
\text { meng } \\
\text { urangi } \\
\text { tingka }\end{array}$ & $\begin{array}{c}\text { Sistem } \\
\text { yang akan } \\
\text { dibagun } \\
\text { memiliki } \\
\text { kelebihan } \\
\text { selain } \\
\text { mengetahui } \\
\text { identitas } \\
\text { kendaraan } \\
\text { yang keluar } \\
\text { masuk, } \\
\text { sistem juga } \\
\text { mengetahui } \\
\text { siapa } \\
\text { pemilik } \\
\text { kendaraan } \\
\text { yang keluar } \\
\text { masuk area } \\
\text { parkir. }\end{array}$ \\
\hline
\end{tabular}




\begin{tabular}{|c|c|c|c|c|c|}
\hline No & Sumber & $\begin{array}{c}\text { Masalah dan } \\
\text { tujuan }\end{array}$ & Metode & Hasil & Kelebihan \\
\hline & & & & $\begin{array}{c}\mathrm{t} \\
\text { pencu } \\
\text { rian } \\
\text { yang } \\
\text { terjadi }\end{array}$ & \\
\hline 4 & $\begin{array}{c}\text { I. T. } \\
\text { Pratama, } \\
\text { "Sistem } \\
\text { Reservasi } \\
\text { Parkir } \\
\text { Berbasis } \\
\text { Web di } \\
\text { Fakultas } \\
\text { Ilmu } \\
\text { Terapan", } \\
\text { e- } \\
\text { Proceedin } \\
\text { g of } \\
\text { Applied } \\
\text { Science, } \\
\text { vol 3, } \\
\text { 2017[8]. }\end{array}$ & $\begin{array}{c}\text { “Terbatasnya } \\
\text { akses untuk } \\
\text { masuk ke area } \\
\text { parkir karena } \\
\text { menggunakan } \\
\text { kartu pegawai } \\
\text { dan mahasiswa } \\
\text { dan kurangnya } \\
\text { lahan parkir di } \\
\text { area Universitas } \\
\text { Telkom”, } \\
\text { "Memberikan } \\
\text { informasi } \\
\text { ketersediaan } \\
\text { lahan parkir } \\
\text { kosong dan } \\
\text { melakukan } \\
\text { reservasi”. }\end{array}$ & $\begin{array}{c}\text { Waterfal } \\
l\end{array}$ & $\begin{array}{c}\text { Siste } \\
\text { m } \\
\text { yang } \\
\text { diban } \\
\text { gung } \\
\text { berha } \\
\text { sil } \\
\text { memb } \\
\text { erikan } \\
\text { infor } \\
\text { masi } \\
\text { keters } \\
\text { ediaa } \\
\text { n } \\
\text { lahan } \\
\text { parkir } \\
\text { koson } \\
\text { g, dan } \\
\text { mamp } \\
\text { u } \\
\text { memb } \\
\text { erikan } \\
\text { konfir } \\
\text { masi } \\
\text { melal } \\
\text { ui sms } \\
\text { untuk } \\
\text { reserv } \\
\text { asi } \\
\text { parkir }\end{array}$ & $\begin{array}{c}\text { Sistem } \\
\text { yang akan } \\
\text { dibagun } \\
\text { memiliki } \\
\text { kelebihan } \\
\text { selain } \\
\text { melihat } \\
\text { ketersediaa } \\
\text { n lahan } \\
\text { parkir yang } \\
\text { kosong, } \\
\text { sistem juga } \\
\text { dapat } \\
\text { memberika } \\
\text { n informasi } \\
\text { mengenai } \\
\text { berapa } \\
\text { biaya yang } \\
\text { akan } \\
\text { dikeluarkan } \\
\text { untuk } \\
\text { setiap kali } \\
\text { reservasi. }\end{array}$ \\
\hline 5 & $\begin{array}{c}\text { G. I. } \\
\text { Wilhamdi } \\
\text { ka, } \\
\text { "Rancang } \\
\text { Bangun } \\
\text { Sistem } \\
\text { Reservasi } \\
\text { Parkir } \\
\text { Online } \\
\text { Pada } \\
\text { Pusat } \\
\text { Perbelanj } \\
\text { aan Di } \\
\text { Kota } \\
\text { Denpasar } \\
\text { Berbasis } \\
\text { Web", } \\
\text { Jurnal } \\
\text { Spektrum } \\
\text {, vol 6, } \\
\text { 2019[9]. }\end{array}$ & $\begin{array}{c}\text { "Pusat } \\
\text { perbelanjaan di } \\
\text { kota Denpasar } \\
\text { memiliki } \\
\text { masalah parkir, } \\
\text { dimana } \\
\text { manajemen } \\
\text { parkir tidak } \\
\text { dapat } \\
\text { mengetahui } \\
\text { ketersediaan slot } \\
\text { parkir", } \\
\text { "Memberikan } \\
\text { kemudahan bagi } \\
\text { pelanggan pusat } \\
\text { perbelanjaan di } \\
\text { kota Denpasar } \\
\text { yang akan } \\
\text { memarkirkan } \\
\text { kendaraannya } \\
\text { dengan } \\
\text { melakukan } \\
\text { reservasi terlebih } \\
\text { dahulu". }\end{array}$ & $\begin{array}{c}\text { Waterfal } \\
l\end{array}$ & $\begin{array}{l}\text { Siste } \\
\mathrm{m} \\
\text { berha } \\
\text { sil } \\
\text { memb } \\
\text { erikan } \\
\text { kemu } \\
\text { dahan } \\
\text { bagi } \\
\text { pelan } \\
\text { ggan } \\
\text { pusat } \\
\text { perbel } \\
\text { anjaa } \\
\mathrm{n} \\
\text { denga } \\
\mathrm{n} \\
\text { melak } \\
\text { ukan } \\
\text { reserv } \\
\text { asi } \\
\text { tempa } \\
\mathrm{t} \\
\text { parkir }\end{array}$ & $\begin{array}{c}\text { Sistem } \\
\text { yang akan } \\
\text { dibagun } \\
\text { memiliki } \\
\text { kelebihan } \\
\text { memberika } \\
\text { n informasi } \\
\text { ketersediaa } \\
\text { n lahan } \\
\text { parkir yang } \\
\text { kosong dan } \\
\text { juga biaya } \\
\text { yang harus } \\
\text { dikeluarkan } \\
\text { untuk } \\
\text { setiap } \\
\text { reservasi. }\end{array}$ \\
\hline 6 & $\begin{array}{c}\text { Y. A. } \\
\text { Ristanti, } \\
\text { "Sistem } \\
\text { Informasi } \\
\text { Pengelola } \\
\text { an } \\
\text { Tempat }\end{array}$ & $\begin{array}{l}\text { "Ketidaktahuan } \\
\text { pengguna parkir } \\
\text { akan } \\
\text { ketersediaan slot } \\
\text { parkir dan } \\
\text { perbedaan sistem } \\
\text { parkir inap dan }\end{array}$ & $\begin{array}{c}\text { Waterfal } \\
l\end{array}$ & $\begin{array}{l}\text { Siste } \\
\text { m } \\
\text { berha } \\
\text { sil } \\
\text { diban } \\
\text { gun, } \\
\text { dan }\end{array}$ & $\begin{array}{c}\text { Sistem } \\
\text { yang akan } \\
\text { dibagun } \\
\text { memiliki } \\
\text { kelebihan } \\
\text { perbedaan } \\
\text { letak parkir }\end{array}$ \\
\hline
\end{tabular}

\begin{tabular}{|c|c|c|c|c|c|}
\hline No & Sumber & $\begin{array}{c}\text { Masalah dan } \\
\text { tujuan }\end{array}$ & Metode & Hasil & Kelebihan \\
\hline & $\begin{array}{c}\text { Parkir } \\
\text { RSUD } \\
\text { Kertoson } \\
\text { o } \\
\text { Nganjuk } \\
\text { Berbasis } \\
\text { Web", } \\
\text { Jurnal } \\
\text { JiSKa, } \\
\text { vol 1, } \\
2016[10] .\end{array}$ & $\begin{array}{c}\text { biasa hanya } \\
\text { dibedakan } \\
\text { menggunakan } \\
\text { karet di bagian } \\
\text { depan } \\
\text { kendaraan", } \\
\text { "Memudahkan } \\
\text { petugas parkir } \\
\text { dalam penerapan } \\
\text { tarif parkir dan } \\
\text { memudahkan } \\
\text { petugas parkir } \\
\text { untuk } \\
\text { mengamankan } \\
\text { kendaraan". }\end{array}$ & & $\begin{array}{c}\text { aplika } \\
\text { si ini } \\
\text { dapat } \\
\text { mena } \\
\text { mpilk } \\
\text { an } \\
\text { lokasi } \\
\text { parkir } \\
\text { yang } \\
\text { masih } \\
\text { tersed } \\
\text { ia, } \\
\text { dan } \\
\text { juga } \\
\text { dapat } \\
\text { meng } \\
\text { hitung } \\
\text { tarif } \\
\text { parkir } \\
\text { untuk } \\
\text { setiap } \\
\text { kenda } \\
\text { raan } \\
\text { secara } \\
\text { otoma } \\
\text { tis } \\
\text { yang } \\
\text { berbe } \\
\text { da } \\
\text { untuk } \\
\text { jangk } \\
\text { a } \\
\text { waktu } \\
\text { tertent } \\
\text { u }\end{array}$ & $\begin{array}{c}\text { inap dan } \\
\text { parkir inap } \\
\text { biasa, jadi } \\
\text { petugas } \\
\text { parkir tidak } \\
\text { akan } \\
\text { bingung } \\
\text { mana yang } \\
\text { parkir inap } \\
\text { menggunak } \\
\text { an QR- } \\
\text { Code dan } \\
\text { mana parkir } \\
\text { inap yang } \\
\text { masih } \\
\text { menggunak } \\
\text { an sistem } \\
\text { yang lama. }\end{array}$ \\
\hline 7 & $\begin{array}{c}\text { A. B. } \\
\text { Pradana, } \\
\text { "Peranca } \\
\text { ngan } \\
\text { Sistem } \\
\text { Perparkir } \\
\text { an } \\
\text { Rendah } \\
\text { Biaya } \\
\text { Berbasis } \\
\text { Ponsel } \\
\text { Cerdas } \\
\text { Android", } \\
\text { Jurnal } \\
\text { Teknik } \\
\text { Elektro, } \\
\text { Vol 11 } \\
\text { No. 1, } \\
\text { 2019[11]. }\end{array}$ & $\begin{array}{l}\text { "Sistem yang } \\
\text { digunakan masih } \\
\text { menggunakan } \\
\text { karcis yang } \\
\text { ditulis oleh } \\
\text { petugas dengan } \\
\text { dicocokan } \\
\text { dengan plat } \\
\text { nomor kendaraan } \\
\text { dan memiliki } \\
\text { peluang untuk } \\
\text { dipalsukan", } \\
\text { "Membuat } \\
\text { sistem yang } \\
\text { meregistrasi } \\
\text { setiap } \\
\text { pengendara yang } \\
\text { akan masuk ke } \\
\text { area parkir } \\
\text { dengan } \\
\text { menggunakan Qr } \\
\text { Code" }\end{array}$ & $\begin{array}{c}\text { Waterfal } \\
l\end{array}$ & $\begin{array}{c}\text { Siste } \\
\text { m } \\
\text { perpar } \\
\text { kiran } \\
\text { meng } \\
\text { atasi } \\
\text { dapat } \\
\text { meng } \\
\text { atasi } \\
\text { masal } \\
\text { ah } \\
\text { sepert } \\
\text { i } \\
\text { pencu } \\
\text { rian, } \\
\text { kesala } \\
\text { han } \\
\text { manu } \\
\text { sia } \\
\text { dan } \\
\text { pengu } \\
\text { ranga } \\
\text { n } \\
\text { pengg } \\
\text { unaan } \\
\text { kertas }\end{array}$ & $\begin{array}{c}\text { Sistem } \\
\text { yang akan } \\
\text { dibangun } \\
\text { akan lebih } \\
\text { mengatasi } \\
\text { masalah } \\
\text { pencurian, } \\
\text { karena } \\
\text { setiap kali } \\
\text { kendaraan } \\
\text { yang } \\
\text { memasuki } \\
\text { area parkir } \\
\text { akan } \\
\text { menggunak } \\
\text { an Qr Code } \\
\text { yang } \\
\text { berbeda. }\end{array}$ \\
\hline 8 & $\begin{array}{c}\text { B. } \\
\text { Paripurno } \\
\text {, } \\
\text { "Rancang } \\
\text { Bangun } \\
\text { Sistem } \\
\text { Pintu }\end{array}$ & $\begin{array}{l}\text { "Sering terjadi } \\
\text { kepadatan } \\
\text { antrian pada } \\
\text { pintu masuk } \\
\text { wisata apalagi } \\
\text { pada saat hari } \\
\text { libur", }\end{array}$ & $\begin{array}{c}\text { Waterfal } \\
l\end{array}$ & $\begin{array}{l}\text { Siste } \\
\text { m } \\
\text { yang } \\
\text { diban } \\
\text { gun } \\
\text { dapat } \\
\text { memp }\end{array}$ & $\begin{array}{c}\text { Sistem } \\
\text { yang akan } \\
\text { dibangun } \\
\text { lebih ramah } \\
\text { lingkungan } \\
\text { karena } \\
\text { sudah tidak }\end{array}$ \\
\hline
\end{tabular}




\begin{tabular}{|c|c|c|c|c|c|}
\hline No & Sumber & $\begin{array}{c}\text { Masalah dan } \\
\text { tujuan }\end{array}$ & Metode & Hasil & Kelebihan \\
\hline & $\begin{array}{c}\text { Masuk } \\
\text { Wisata } \\
\text { Berbasis } \\
\text { Arduino } \\
\text { Dan Qr } \\
\text { Code", } \\
\text { Prosiding } \\
\text { Seminar } \\
\text { Nasional } \\
\text { Hasil } \\
\text { Penelitian } \\
\text { dan } \\
\text { Pengabdi } \\
\text { an } \\
\text { Kepada } \\
\text { Masyarak } \\
\text { at, Vol 3 } \\
\text { No. 1, } \\
\text { 2018[12]. }\end{array}$ & $\begin{array}{c}\text { "Pengunjung } \\
\text { tempat wisata } \\
\text { hanya perlu } \\
\text { memesan tiket } \\
\text { melalui website } \\
\text { yang telah } \\
\text { disediakan agar } \\
\text { tidak terjadi lagi } \\
\text { kepadatan } \\
\text { antrian pada } \\
\text { pintu masuk" }\end{array}$ & & $\begin{array}{c}\text { ermud } \\
\text { ah } \\
\text { penge } \\
\text { cekan } \\
\text { tiket } \\
\text { masu } \\
\text { k } \\
\text { wisata } \\
\text { yang } \\
\text { dapat } \\
\text { meng } \\
\text { urangi } \\
\text { antria } \\
\text { n } \\
\text { pada } \\
\text { pintu } \\
\text { masu } \\
\text { k. }\end{array}$ & $\begin{array}{c}\text { menggunak } \\
\text { an lagi tiket } \\
\text { kertas yang } \\
\text { harus di } \\
\text { print } \\
\text { terlebih } \\
\text { dahulu. }\end{array}$ \\
\hline
\end{tabular}

Melihat dari 8 (delapan) penelitian terkait diatas dapat disimpulkan bahwa dalam membuat suatu sistem parkir harus melihat dari sisi pengendara, kebanyakan masalah yang terjadi adalah sering sekali terdapat kepadatan antrian pada pintu masuk dikarenakan susahnya struk parkir yang keluar dari mesin parkir yang mengakibatkan palang pintu parkir tidak terbuka, ataupun terjadi kepadatan antrian pada pintu keluar dikarenakan struk parkir pengendara yang hilang. Dan solusi dari penelitian tersebut yaitu membuat suatu sistem parkir yang dapat membuat struk parkir tidak lagi menggunakan kertas, atau bisa dibilang $e$-struk, dengan $e$-struk pengendara tidak lagi akan kehilangan struk parkir yang digunakan untuk keluar dari area parkir. Maka dari itu, penelitian-penelitian terdahulu tersebut terkait dengan penelitian penulis.

\section{METODOLOGI PENELITIAN}

\section{A. Teknik Pengumpulan Data}

Pengumpulan data dilakukan dengan melakukan observasi dan wawancara dengan pengguna dan staf Pt. Sanggraha Daksamitra.

1) Observasi, yaitu melihat secara langsung sistem parkir yang sedang berjalan di Pt.sanggraha Daksamitra.

2) Wawancara, yaitu melakukan wawancara langsung dengan pengendara parkir dan juga staf Pt.Sanggraha Daksamitra

3) Studi Literatur, yaitu mengumpulkan materi-materi jurnal terdahulu yang berhubungan dengan penelitian penulis.

\section{B. Metode Analisa}

Setelah mendapatkan data-data yang diperlukan dari hasil observasi, wawancara dan juga studi literatur dilanjutkan dengan menganalisa sistem yang sedang berjalan. Dalam penelitian ini, metode yang digunakan untuk menganalisa sistem yang berjalan menggunakan Fishbone diagram. Fishbone diagram adalah salah satu metode untuk menganalisa suatu masalah atau kondisi, terkadang diagram ini sering disebut diagram sebab-akibat atau cause effect diagram. Diagram ini menunjukan dampak atau akibat dari sebuah permasalahan, dengan segala penyebabnya. Akibat dituliskan sebagai moncong kepala, sedangkan tulang-tulang ikan diisi oleh sebab-sebab sesuai dengan permasalahannya.

\section{Diagram Alur Penelitian}

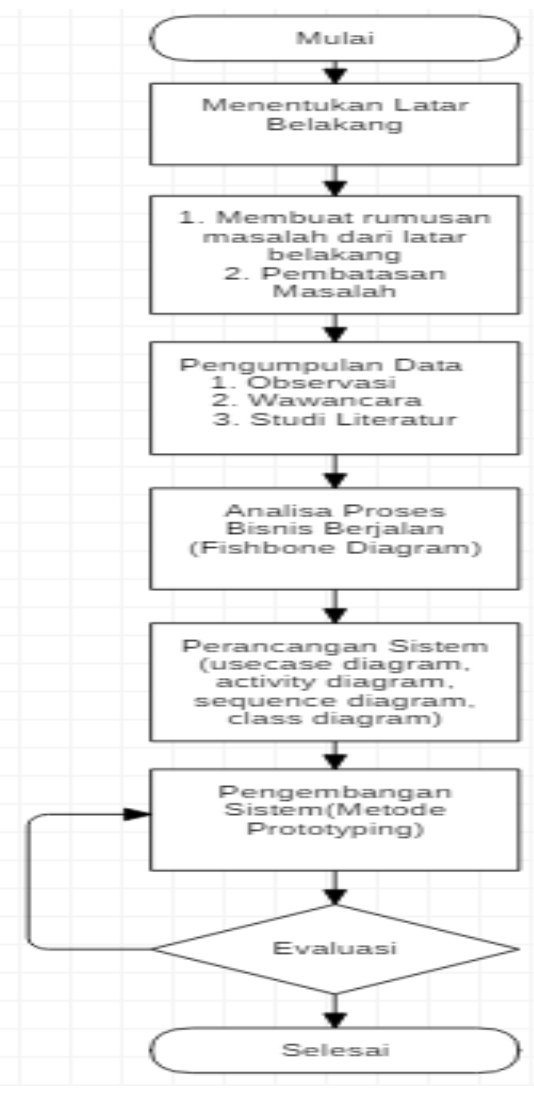

Gambar 1. Diagram Alur Penelitian

\section{HASIL DAN PEMBAHASAN}

\section{A. Analisa Proses Bisnis}

Sistem yang saat ini digunakan masih rentan kekurangan, oleh karena itu dilakukan analisa terhadap proses bisnis yang sedang berjalan dengan menggunakan metode fishbone diagram. Metode ini merupakan diagram sebab-akibat atau cause - effect yang berbentuk seperti tulang ikan. Fishbone diagram menunjukan dampak atau akibat mengenai apa-apa saja yang menjadi akar permasalahan dalam sistem yang sedang dianalisa dengan segala penyebab yang mungkin timbul. Penjelasan analisa proses bisnis menggunakan metode fishbone diagram dapat dilihat pada gambar berikut: 


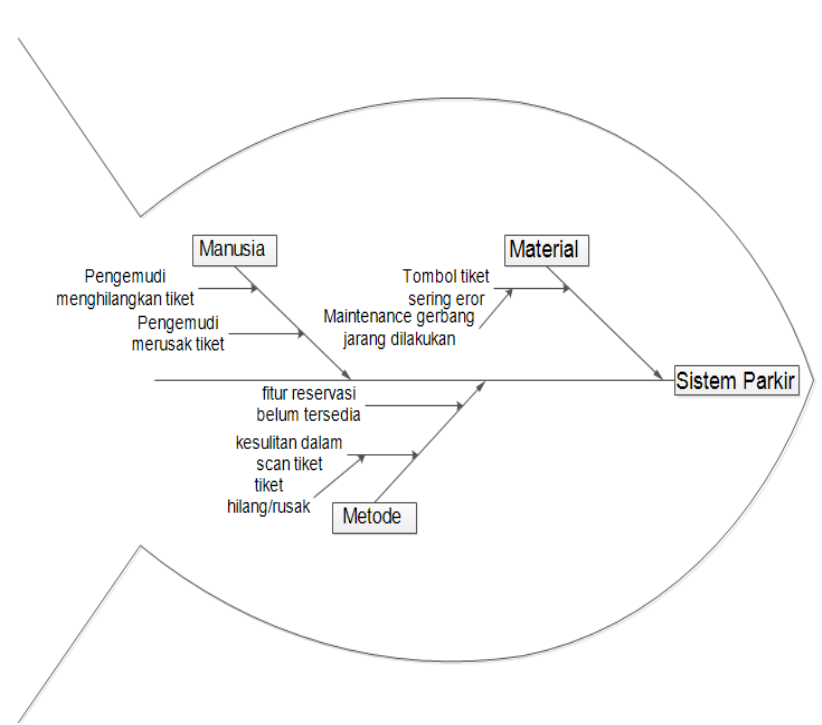

Gambar 2. Fishbone Diagram

Dari gambar fishbone diagram diatas, dapat dilihat bahwa terdapat 3 sebab yaitu Material, Manusia dan Metode yang menjadikan sistem yang lama perlu diganti dengan sistem yang baru. Dari ketiga sebab tersebut yang sering sekali terjadi di area parkir adalah faktor manusia yaitu pengemudi kehilangan tiket dan pengemudi merusak tiket yang menyebabkan terjadinya antrian di pintu keluar parkir. Meskipun dua faktor yang lain jarang terjadi di area parkir, tentunya pengemudi ataupun pemilik lahan parkir menginginkan sistem yang sedikit masalah didalamnya. Jadi kesimpulan yang didapat dari analisa yang menggunakan fishbone diagram diatas yaitu membuat suatu sistem parkir yang tidak lagi menggunakan tiket kertas sebagai media keluar masuk area parkir, dan pengemudi dapat mengetahui ketersediaan lot parkir agar tidak harus memutar balikan kendaraannya karena lot parkir yang sudah penuh.

\section{B. Perancangan Sistem Usulan}

Pada perancangan sistem yang diusulkan, UML (Unifed Modeling Language) yang digunakan yaitu usecase diagram dan class diagram. Berikut perancangan usecase dan class diagram sistem usulan untuk pengembangan aplikasi reservasi parkir inap dapat dilihat pada gambar 3 dan 4 dibawah.

\section{Class Diagram}

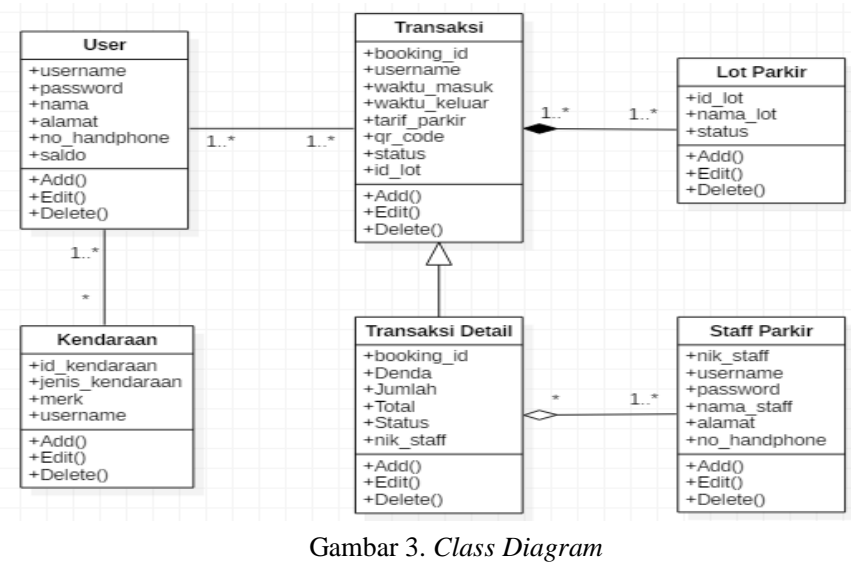

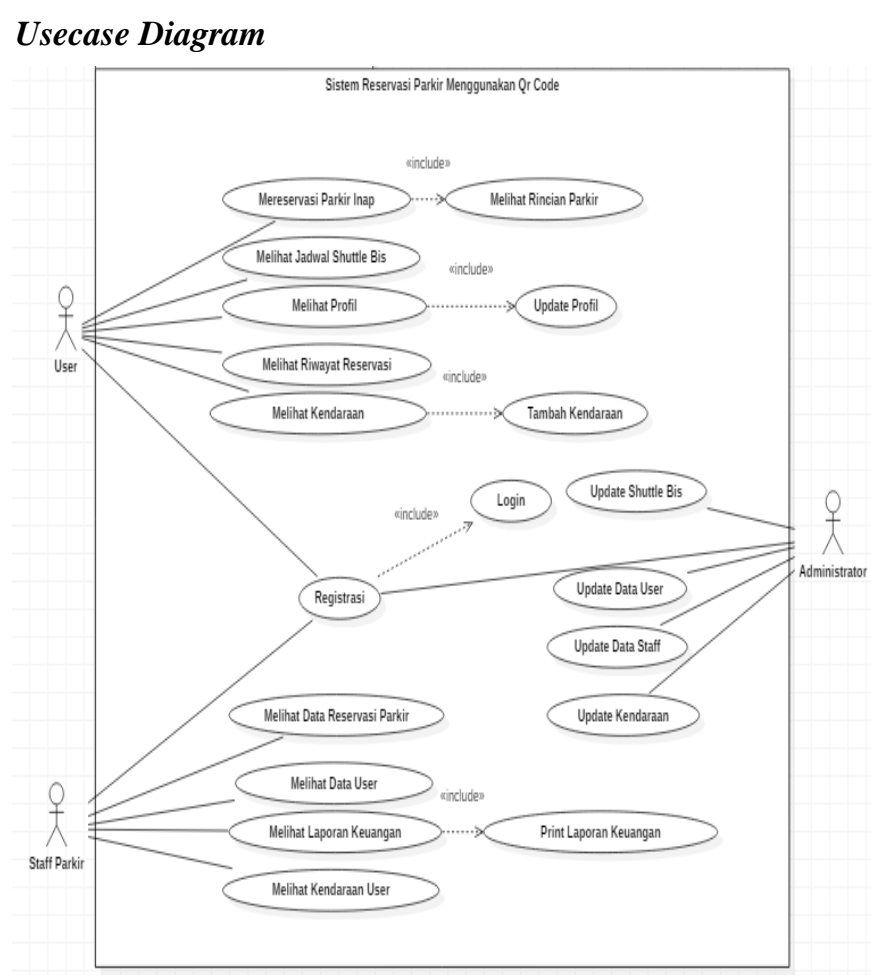

Gambar 4. Usecase Diagram

\section{Pendefinisian aktor:}

User: User adalah pengendara kendaraan yang hendak memarkirkan kendaraannya di area parkir Pt.Sanggraha Daksamitra, user dapat reservasi parkir dan juga dapat melihat sisa lot parkir yang tersedia

Staf Parkir: Staf parkir adalah staf yang dapat mengelola data reservasi parkir, termasuk melihat laporan keuangan dan juga data user

Administrator: Administrator adalah admin yang dapat mengelola segala sesuatu hal yang ada di dalam sistem reservasi parkir.

\section{Rancangan Antarmuka Sistem Usulan}

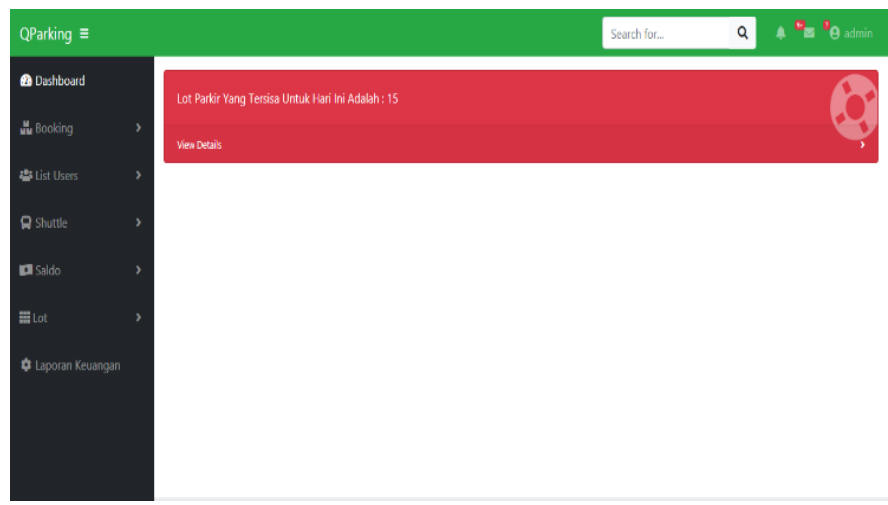

Gambar 5. Tampilan Dashboard Qparking

Halaman Dashboard, yaitu halaman yang dapat dilihat user, staf parkir ataupun admin yang berisi tentang sisa lot 
parkir yang tersedia dan di bagian kiri terdapat menu - menu yang dapat digunakan seperti reservasi baru, ataupun melihat riwayat transaksi seperti gambar 5.

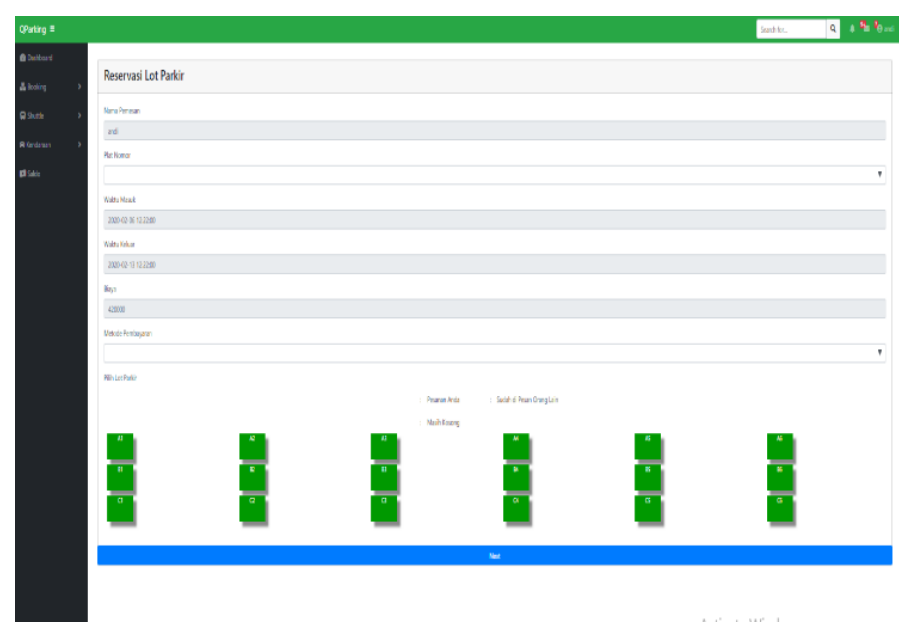

Gambar 6. Tampilan Tambah Reservasi

Halaman Tambah Reservasi, yaitu halaman yang dapat dilihat user, staf parkir ataupun admin. Halaman ini berisi form yang harus diisi oleh user, staf parkir ataupun admin yang hendak melakukan reservasi baru seperti gambar 6 .
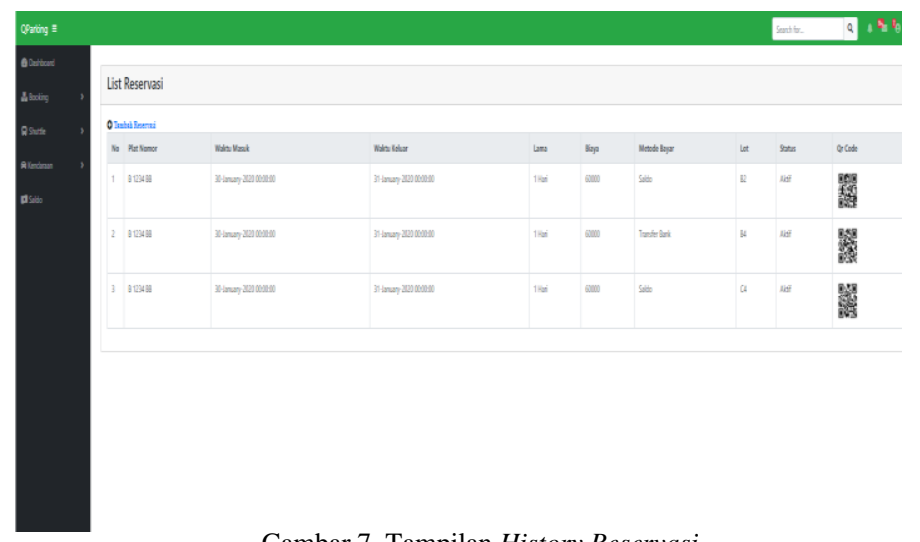

Gambar 7. Tampilan History Reservasi

Halaman History Reservasi, yaitu halaman yang dapat dilihat user, staf parkir ataupun admin. Halaman ini berisi tentang data-data seperti plat nomor kendaraan, waktu masuk, waktu keluar hingga $Q R$-Code riwayat reservasi yang dilakukan oleh user seperti gambar 7 .

Setelah sistem reservasi parkir inap berbasis web selesai, dilakukan pengujian sistem menggunakan blackbox testing yang diuraikan pada Tabel 2.

Dari hasil pengujian blackbox testing pada halaman login dilakukan empat kali pengujian. Pengujian pertama admin tidak mengisi username dan password, maka sistem memunculkan "Please fill out this field" pada kolom username. Pengujian tahap kedua admin mengisi username tapi tidak mengisi password, maka sistem memunculkan "Please fill out this field" pada kolom password. Pengujian tahap ketiga admin mengisi username dan password yang tidak sesuai, maka sistem memunculkan "Username/password salah, silahkan periksa kembali". Pengujian terakhir admin mengisi username dan password yang sesuai, maka sistem menampilkan halaman dashboard.

TABLE II. HASIL BLACKBOX TESTING HALAMAN LOGIN

\begin{tabular}{|c|c|c|c|c|c|}
\hline No & $\begin{array}{c}\text { Skenario } \\
\text { Unit }\end{array}$ & $\begin{array}{l}\text { Test } \\
\text { Case }\end{array}$ & $\begin{array}{c}\text { Hasil yang } \\
\text { diharapkan }\end{array}$ & $\begin{array}{c}\text { Hasil } \\
\text { Pengujian }\end{array}$ & Kesimpulan \\
\hline 1 & $\begin{array}{l}\text { Username } \\
\text { dan } \\
\text { password } \\
\text { tidak diisi } \\
\text { kemudian } \\
\text { klik } \\
\text { tombol } \\
\text { login }\end{array}$ & $\begin{array}{l}\text { Usernam } \\
\text { e: } \\
\text { (kosong) } \\
\text { Password } \\
: \\
\text { (kosong) }\end{array}$ & $\begin{array}{l}\text { Sistem akan } \\
\text { menolak } \\
\text { akses user } \\
\text { dan } \\
\text { menampilkan } \\
\text { "Please fill } \\
\text { out this field } \\
\text { pada kolom } \\
\text { username" }\end{array}$ & $\begin{array}{l}\text { Sesuai } \\
\text { harapan }\end{array}$ & Valid \\
\hline 2 & $\begin{array}{l}\text { Mengisi } \\
\text { Username } \\
\text { dan } \\
\text { password } \\
\text { tidak diisi } \\
\text { kemudian } \\
\text { klik } \\
\text { tombol } \\
\text { login } \\
\end{array}$ & $\begin{array}{l}\text { Usernam } \\
\text { e: } \\
\text { (admin) } \\
\text { Password } \\
: \\
\text { (kosong) }\end{array}$ & $\begin{array}{l}\text { Sistem akan } \\
\text { menolak } \\
\text { akses user } \\
\text { dan } \\
\text { menampilkan } \\
\text { "Please fill } \\
\text { out this field } \\
\text { pada kolom } \\
\text { password" }\end{array}$ & $\begin{array}{l}\text { Sesuai } \\
\text { harapan }\end{array}$ & Valid \\
\hline 3 & $\begin{array}{l}\text { Mengisi } \\
\text { Username } \\
\text { dan } \\
\text { password } \\
\text { yang salah } \\
\text { kemudian } \\
\text { klik } \\
\text { tombol } \\
\text { login }\end{array}$ & $\begin{array}{l}\text { Usernam } \\
\text { e: } \\
\text { (admin) } \\
\text { Password } \\
\text { : (salah) }\end{array}$ & $\begin{array}{l}\text { Sistem akan } \\
\text { menolak dan } \\
\text { menampilkan } \\
\text { "Username/p } \\
\text { assword } \\
\text { salah, } \\
\text { silahkan } \\
\text { periksa } \\
\text { kembali" }\end{array}$ & $\begin{array}{l}\text { Sesuai } \\
\text { harapan }\end{array}$ & Valid \\
\hline 4 & $\begin{array}{l}\text { Mengisi } \\
\text { username } \\
\text { dan } \\
\text { password } \\
\text { dengan } \\
\text { data yang } \\
\text { benar } \\
\text { kemudian } \\
\text { klik } \\
\text { tombol } \\
\text { login }\end{array}$ & $\begin{array}{l}\text { Usernam } \\
\text { e: } \\
\text { (admin) } \\
\text { Password } \\
\text { : (admin) }\end{array}$ & $\begin{array}{l}\text { Sistem akan } \\
\text { menerima } \\
\text { akses login } \\
\text { kemudian } \\
\text { langsung } \\
\text { menampilkan } \\
\text { halaman } \\
\text { dashboard }\end{array}$ & $\begin{array}{l}\text { Sesuai } \\
\text { harapan }\end{array}$ & Valid \\
\hline
\end{tabular}

TABLE III. HASIL BACKBOX TESTING HALAMAN RESERVASI BARU

\begin{tabular}{|c|c|c|c|c|c|}
\hline No & $\begin{array}{c}\text { Skenario } \\
\text { Unit }\end{array}$ & Test Case & $\begin{array}{c}\text { Hasil yang } \\
\text { diharapkan }\end{array}$ & $\begin{array}{c}\text { Hasil } \\
\text { Pengujian }\end{array}$ & $\begin{array}{c}\text { Kesimpu } \\
\text { lan }\end{array}$ \\
\hline 1 & $\begin{array}{l}\text { Pengendar } \\
\mathrm{a} \\
\text { mengisika } \\
\mathrm{n} \text { form } \\
\text { reservasi } \\
\text { parkir } \\
\text { baru } \\
\text { kemudian } \\
\text { klik next }\end{array}$ & $\begin{array}{l}\text { Nama } \\
\text { pemesan: } \\
\text { andi } \\
\text { Plat nomor: } \\
\text { (kosong) } \\
\text { Waktu } \\
\text { masuk: } \\
\text { 2020-02-20 } \\
\text { Waktu } \\
\text { keluar: } \\
\text { 2020-02-21 } \\
\text { Metode } \\
\text { Pembayaran: } \\
\text { Saldo lot } \\
\text { Pilih parkir: A1 }\end{array}$ & $\begin{array}{l}\text { Sistem akan } \\
\text { menolak dan } \\
\text { menampilka } \\
\text { n "Harap } \\
\text { Masukan } \\
\text { plat nomor" }\end{array}$ & $\begin{array}{l}\text { Sesuai } \\
\text { harapan }\end{array}$ & Valid \\
\hline 2 & $\begin{array}{l}\text { Pengendar } \\
\mathrm{a} \\
\text { mengisika } \\
\mathrm{n} \quad \text { form } \\
\text { reservasi } \\
\text { parkir } \\
\text { baru }\end{array}$ & $\begin{array}{l}\text { Nama } \\
\text { pemesan: } \\
\text { andi } \\
\text { Plat nomor: } \\
\text { B1234BB } \\
\text { Waktu } \\
\text { masuk: }\end{array}$ & $\begin{array}{l}\text { Sistem akan } \\
\text { menolak dan } \\
\text { menampilka } \\
\mathrm{n} \text { "Harap } \\
\text { memilih lot } \\
\text { parkir yang } \\
\text { tersedia" }\end{array}$ & $\begin{array}{l}\text { Sesuai } \\
\text { harapan }\end{array}$ & Valid \\
\hline
\end{tabular}


Jurnal SISFOKOM (Sistem Informasi dan Komputer), Volume 09, Nomor 03, PP 302 - 309

\begin{tabular}{|c|c|c|c|c|c|}
\hline No & $\begin{array}{c}\text { Skenario } \\
\text { Unit }\end{array}$ & Test Case & $\begin{array}{c}\text { Hasil yang } \\
\text { diharapkan }\end{array}$ & $\begin{array}{c}\text { Hasil } \\
\text { Pengujian }\end{array}$ & $\begin{array}{c}\text { Kesimpu } \\
\text { lan }\end{array}$ \\
\hline & $\begin{array}{l}\text { kemudian } \\
\text { klik next }\end{array}$ & $\begin{array}{l}\text { 2020-02-20 } \\
\text { Waktu } \\
\text { keluar: } \\
\text { 2020-02-21 } \\
\text { Metode } \\
\text { Pembayaran: } \\
\text { Saldo } \\
\text { Pilih lot } \\
\text { parkir: } \\
\text { (kosong) }\end{array}$ & & & \\
\hline 3 & $\begin{array}{l}\text { Pengendar } \\
\text { a } \\
\text { mengisika } \\
\text { n form } \\
\text { reservasi } \\
\text { parkir } \\
\text { baru } \\
\text { kemudian } \\
\text { klik next }\end{array}$ & $\begin{array}{l}\text { Nama } \\
\text { pemesan: } \\
\text { andi } \\
\text { Plat nomor: } \\
\text { B1234BB } \\
\text { Waktu } \\
\text { masuk: } \\
\text { 2020-02-20 } \\
\text { Waktu } \\
\text { keluar: } \\
\text { 2020-02-21 } \\
\text { Metode } \\
\text { Pembayaran: } \\
\text { Saldo lot } \\
\text { Pilih lo } \\
\text { parkir: A1 }\end{array}$ & $\begin{array}{l}\text { Sistem akan } \\
\text { memproses } \\
\text { data dan } \\
\text { menyimpan } \\
\text { ke database } \\
\text { kemudian } \\
\text { user dapat } \\
\text { melihat } \\
\text { history } \\
\text { reservasi }\end{array}$ & $\begin{array}{l}\text { Sesuai } \\
\text { harapan }\end{array}$ & Valid \\
\hline
\end{tabular}

Dari hasil pengujian blackbox testing pada halaman reservasi baru dilakukan tiga kali pengujian. Pengujian pertama admin tidak memasukan plat nomor pada form, maka sistem menampilkan "Harap masukan plat nomor". Pengujian tahap kedua admin tidak memilih lot parkir yang tersedia, maka sistem menampilkan "Harap memilih lot parkir yang tersedia". Lalu pada pengujian terakhir admin mengisi semua kolom dengan benar, maka sistem menyimpan data yang diisi oleh admin ke database.

TABLE IV. HASIL BLACKBOX TESTING HALAMAN TAMBAH STAF/USER

\begin{tabular}{|c|c|c|c|c|c|}
\hline No & $\begin{array}{c}\text { Skenario } \\
\text { Unit }\end{array}$ & Test Case & $\begin{array}{c}\text { Hasil yang } \\
\text { diharapkan }\end{array}$ & $\begin{array}{c}\text { Hasil } \\
\text { Pengujian }\end{array}$ & $\begin{array}{c}\text { Kesimpu } \\
\text { lan }\end{array}$ \\
\hline 1 & $\begin{array}{l}\text { Admin } \\
\text { mengisika } \\
\mathrm{n} \quad \text { form } \\
\text { tambah } \\
\text { staf/user } \\
\text { kemudian } \\
\text { klik next }\end{array}$ & $\begin{array}{l}\text { Username: } \\
\text { andi } \\
\text { Password: } \\
\text { (kosong) } \\
\text { Nama: } \\
\text { andi } \\
\text { Alamat: j1. } \\
\text { Meruya } \\
\text { selatan } \\
\text { no.1 } \\
\text { Nomor } \\
\text { Handphon } \\
\text { e: } \\
081234567 \\
8910\end{array}$ & $\begin{array}{l}\text { Sistem akan } \\
\text { menolak dan } \\
\text { menampilkan } \\
\text { "Harap } \\
\text { Masukan } \\
\text { password" }\end{array}$ & $\begin{array}{l}\text { Sesuai } \\
\text { harapan }\end{array}$ & Valid \\
\hline 2 & $\begin{array}{l}\text { Admin } \\
\text { mengisika } \\
\mathrm{n} \text { form } \\
\text { tambah } \\
\text { staf/user } \\
\text { dengan } \\
\text { username } \\
\text { yang } \\
\text { sudah ada } \\
\text { kemudian } \\
\text { klik next }\end{array}$ & $\begin{array}{l}\text { Username: } \\
\text { admin } \\
\text { Password: } \\
\text { admin } \\
\text { Nama: } \\
\text { admin } \\
\text { Alamat: j1. } \\
\text { Meruya } \\
\text { selatan } \\
\text { no.1 } \\
\text { Nomor } \\
\text { Handphon } \\
\text { e: }\end{array}$ & $\begin{array}{l}\text { Sistem akan } \\
\text { menolak dan } \\
\text { menampilkan } \\
\text { "Username } \\
\text { telah } \\
\text { terpakai" }\end{array}$ & $\begin{array}{l}\text { Sesuai } \\
\text { harapan }\end{array}$ & Valid \\
\hline
\end{tabular}

\begin{tabular}{|c|c|c|c|c|c|}
\hline No & $\begin{array}{c}\text { Skenario } \\
\text { Unit }\end{array}$ & Test Case & $\begin{array}{c}\text { Hasil yang } \\
\text { diharapkan }\end{array}$ & $\begin{array}{c}\text { Hasil } \\
\text { Pengujian }\end{array}$ & $\begin{array}{c}\text { Kesimpu } \\
\text { lan }\end{array}$ \\
\hline & & $\begin{array}{l}081234567 \\
8910\end{array}$ & & & \\
\hline 3 & $\begin{array}{l}\text { Admin } \\
\text { mengisika } \\
\mathrm{n} \quad \text { form } \\
\text { tambah } \\
\text { staf/user } \\
\text { kemudian } \\
\text { klik next }\end{array}$ & $\begin{array}{l}\text { Username: } \\
\text { andi } \\
\text { Password: } \\
\text { andi } \\
\text { Nama: } \\
\text { andi } \\
\text { Alamat: jl. } \\
\text { Meruya } \\
\text { selatan } \\
\text { no.1 } \\
\text { Nomor } \\
\text { Handphon } \\
\text { e: } \\
\text { 081234567 } \\
8910\end{array}$ & $\begin{array}{l}\text { Sistem akan } \\
\text { memproses } \\
\text { data dan } \\
\text { menyimpan } \\
\text { ke database }\end{array}$ & $\begin{array}{l}\text { Sesuai } \\
\text { harapan }\end{array}$ & Valid \\
\hline
\end{tabular}

Dari hasil pengujian blackbox testing pada halaman tambah staf atau user dilakukan tiga kali pengujian. Pengujian pertama adalah admin tidak mengisi password, maka sistem menampilkan "Harap masukan password". Pengujian tahap kedua adalah admin mengisi username yang sudah ada, maka sistem menampilkan "Username telah terpakai". Lalu pada pengujian terakhir admin mengisi data dengan benar, maka sistem memproses data dan menyimpan ke database.

\section{PENUTUP}

Berdasarkan penelitian yang telah dilakukan, maka dapat disimpulkan bahwa penelitian reservasi parkir inap di Pt. Sanggraha Daksamitra menghasilkan sebuah sistem reservasi parkir inap menggunakan qr-code. Dengan adanya sistem reservasi parkir inap, parkir inap yang dilakukan di area $\mathrm{Pt}$. Sanggraha Daksamitra menjadi lebih memudahkan bagi pengguna parkir, karena pengguna dapat mengetahui ketersediaan lot parkir sebelum akhirnya menentukan untuk reservasi atau tidak. Sistem ini juga dapat mengurangi penumpukan kendaraan yang sering terjadi di area keluar parkir karena tidak ada lagi struk parkir yang hilang.

Setelah melakukan analisa dan memberikan kesimpulan, maka penulis memberikan saran yang dapat dijadikan bahan untuk mengembangkan sistem agar lebih baik, adapun sarannya perlu adanya sosialisasi yang harus dilakukan agar pengguna parkir mengetahui sistem parkir yang baru. Sistem parkir lebih baik lagi bila dilengkapi dengan sensor yang dapat mengetahui kendaraan masih berada di lokasi parkir atau tidak. Sistem parkir yang menggunakan kamera pengawas di setiap sudut parkir lebih memberikan kenyamanan bagi pengguna, karena pengguna nantinya dapat melihat langsung kendaraannya melalui kamera pengawas yang telah di sediakan.

\section{DAFTAR PUSTAKA}

[1] Rahmawati \& Rahman, "Sistem Pengamanan Keaslian Ijasah Menggunakan QR Code dan Algoritma Based64", JUSI Vol. I, No.2, September 2011.

[2] N Hainalkar. Gayatri, and S. Vanjale. Mousami, "Smart parking system with pre \& post reservation, billing and traffic app", Intelligent Computing and Control Systems (ICICCS), 2017. 
[3] Budiman. A. \& Triono. J, "Sistem Informasi Parkir Kendaraan Bermotor Berbasis Android”, Jurnal Ilmiah Ilmu-Ilmu Teknik Vol 1, ISSN: 2502$7042,2016$.

[4] Rouillard. J, "Contextual QR Codes", Proceedings of the Third International Multi-Conference on Computing in the Global Information Technology, ICCGI, Athens, Greece, 2008.

[5] M. T. Hidayat, "Pengembangan Modul Client Pada Sistem Parkir Pintar Berbasis Quick Response Code (QR CODE)", e-Proceeding of Engineering, vol.6, 2019.

[6] I. G. Tofik, "Perancangan Sistem Parkir QR CODE Menggunakan Mikrokontroler Arduino Berbasis Android", Seminar Nasional Teknologi Informasi dan Multimedia, 2017.

[7] A. Triagi, "Sistem Informasi Manajemen Parkir Kendaraan Menggunakan Teknologi QR Code Berbasis Desktop", Seminar
Teknologi Majalengka, 2018.

[8] I. T. Pratama, "Sistem Reservasi Parkir Berbasis Web di Fakultas Ilmu Terapan", e-Proceeding of Applied Science, vol 3, 2017.

[9] G. I. Wilhamdika, "Rancang Bangun Sistem Reservasi Parkir Online Pada Pusat Perbelanjaan Di Kota Denpasar Berbasis Web", Jurnal Spektrum, vol 6, 2019.

[10] Y. A. Ristanti, "Sistem Informasi Pengelolaan Tempat Parkir RSUD Kertosono Nganjuk Berbasis Web", Jurnal JiSKa, vol 1, 2016.

[11] A. B. Pradana, "Perancangan Sistem Perparkiran Rendah Biaya Berbasis Ponsel Cerdas Android”, Jurnal Teknik Elektro, Vol 11 No. 1, 2019.

[12] B. Paripurno, "Rancang Bangun Sistem Pintu Masuk Wisata Berbasis Arduino Dan Qr Code", Prosiding Seminar Nasional Hasil Penelitian dan Pengabdian Kepada Masyarakat, Vol 3 No. 1, 2018 